\title{
Health service use in families where children enter public care: a nested case control study using the General Practice Research Database
}

\author{
Douglas E Simkiss ${ }^{1 *}$, Nicholas J Spencer ${ }^{2}$, Nigel Stallard ${ }^{3}$ and Margaret Thorogood ${ }^{4}$
}

\begin{abstract}
Background: At least 3\% of children spend some of their childhood in public care and, as a group, have poor outcomes across a range of education, employment, health and social care outcomes. Research, using social care or government datasets, has identified a number of risk factors associated with children entering public care but the utility of risk factors in clinical practice is not established. This paper uses routine primary health care data to see if risk factors for children entering public care can be identified in clinical practice.

Methods: A nested case control methodology using routine primary care data from the United Kingdom. Health service use data were extracted for the 12 months before the case child entered public care and compared with 12 months of data for four control mother child pairs per case pair, matched on the age and sex of the child and the general practice. Exposures of interest were developed from a systematic review of the literature on risk factors associated with children entering public care.
\end{abstract}

Results: Conditional logistic regression was used to investigate the combined effect of more than one exposure of interest. Maternal mental illness (OR 2.51,95\% Cl 1.55-4.05), maternal age at birth of the child, socio-economic status (5 $5^{\text {th }}$ quintile vs. $1^{\text {st }}$ quintile $\left.\mathrm{OR} 7.14,95 \% \mathrm{Cl} 2.92-17.4\right)$, maternal drug use (OR 28.8, 95\% Cl 2.29-363), non attendance at appointments (OR 2.42, 95\% Cl 1.42-4.14), child mental illness (OR 2.65, 95\% Cl 1.42-4.96) and child admission to hospital (OR 3.31, 95\% Cl 1.21-9.02) were all significantly associated with children entering public care. Maternal use of primary care contraception services was negatively associated with children entering public care (OR 0.52, 95\% Cl 0.31-0.87).

Conclusions: Differences in health service use can be identified from routine primary care data in mother child pairs where children enter public care after controlling for maternal age and socio-economic status. The interaction between different risk factors needs testing in a cumulative risk model using longitudinal datasets.

\section{Background}

Children in public care are a vulnerable group with ' $a$ higher level of health, mental health and health promotion needs than others of the same age' [1]. A large study of the mental health of children in public care in England showed a fivefold increase in mental disorder compared to other children, with conduct disorder contributing most of the difference in childhood psychopathology [2]. Elevated mental illness prevalence rates for children in public care are also reported from the

\footnotetext{
* Correspondence: d.e.simkiss@warwick.ac.uk

${ }^{1}$ Health Sciences Research Institute, Warwick Medical School, University of Warwick, Coventry CV47AL, UK

Full list of author information is available at the end of the article
}

USA [3,4], Australia [5] and Denmark [6]. Research shows that children in public care are under immunised [7] and providing information on immunisation status to social workers has not improved immunisation coverage [8]. In addition young people in public care have high levels of risk taking behaviours including smoking, alcohol and drug use [9-12] and are sexually active at an early age with high rates of teenage pregnancy recorded from the United Kingdom [13] and Sweden [14,15].

Policy and practice developments in the United Kingdom are leading to improvements in the health and wellbeing of children in public care $[16,17]$ but, nevertheless, there is evidence from the UK and Sweden that young people in public care do less well than other

\section{Biomed Central}


young people across all five Every Child Matters [18] domains (be healthy, stay safe, enjoy and achieve, make a positive contribution and achieve economic wellbeing) [2,19-23].

At the start of a period of public care, one study found half of children had a diagnosable mental illness [24] and other research shows that they are more often involved in risk taking behaviours including early and unprotected sexual activity, smoking, alcohol and drug misuse than other young people of the same age [24-26]. Many younger children enter public care with developmental delay and a history of maltreatment including abuse and neglect which can have long term consequences.

These findings at entry to public care suggest that health issues are present and could be identified before entry to care; whilst children are living at home. To understand what is known of the health characteristics and social circumstances of families where children are subsequently taken into public care, a systematic review of risk factors associated with children entering public care was conducted [27]. This found that for mothers of children who enter public care, there is evidence of association with socioeconomic status [28-31], benefit receipt $[28,29,32]$, single parenthood [28,31,32], ethnicity $[28,31]$, age $[20,21,29]$, disability [31], smoking in pregnancy [33], mental illness [29,33], alcohol misuse [34], sexually transmitted infections [35] and learning difficulties [29]. For children who enter public care, there is evidence of association with low birth weight and prematurity [33], disability [32], injuries [32], congenital syphilis [35] and attendance at Accident and Emergency departments [32]. However, much of the available information is derived from cohort studies of populations selected because families are already being in contact with social care services and that very little research has been carried out in the UK.

One important and previously unexplored source of information on risk factors leading up to a child entering public care is the data collected in primary health care, this has the advantage that it is routinely collected in practice, is almost universal in a UK context and could provide much more detailed health information than previous research on health associations for children entering public care. In addition, this dataset allows the health risk factors to be assessed alongside socioeconomic status data, which may be confounding previously described health associations.

In this paper, we use primary health care data to explore the risk factors associated with children entering public care to address two research questions:

1. Are risk factors associated with children entering public care identifiable from the health records of mothers of children who enter public care compared to mothers whose children do not enter public care?

2. Are risk factors associated with entering public care identifiable from the primary care health records of these children compared to children who do not enter public care?

\section{Methods}

\section{Ethical approval}

In 2006, the Medical Research Council (MRC) began a scheme with the Medicines and Healthcare products Regulatory Agency (MHRA) to provide free access to GPRD data for up to 50 approved and academically led proposals per year. This project was awarded a licence as part of the MRC-MHRA collaboration and was approved by the Scientific and Ethical Advisory Group of GPRD as a suitable study.

We carried out a case control study; nested within a large primary care database: the General Practice Research Database (GPRD). We reviewed contemporaneous medical records of mother child pairs (dyads) where the child was recorded as having entered public care.

\section{Case and control definitions}

We defined a case as a mother-child dyad, where both have been registered at the general practice and the child was recorded as having gone into public care. The period of time for which the primary care records are examined is a crucial decision. Too short a time period would risk missing key events, while too long would risk losing cases where the family were not registered with the primary care practice for long enough. We chose to analyse a period of 12 months before the child enters public care.

We chose to study the oldest child in the family when more than one sibling was taken into public care because this child is likely to have the most available health data. Because we required at least 12 months of data to be available, only children aged more than 1 year at entry to public care were included in the study. For each case dyad, staff at GPRD randomly selected four control dyads, matched by age and sex of the child and general practice.

\section{The General Practice Research Database}

The GPRD is the largest database of anonymous longitudinal primary care information in the world. It was established in 1987, has 44 million patient years of high quality validated data, 3.6 million active patient records and 13 million records in total [36]. The database contains information on clinical events, coded by general practitioners at consultations, prescriptions, referrals to 
secondary care for appointments or investigations and information on admissions to hospital, all events are coded using Read/OXMIS codes, akin to International Classification of Disease codes for clinical diagnoses. There are Read/OXMIS codes identifying that a child has entered public care. The Townsend score [37], as a measure of a measure of socio-economic status (SES) based on post-codes, was available for patients living in part of England. Because we believed that socio-economic status was likely to be an important risk factor for entering care and a potential confounding factor for other associations previously described in the literature, we limited our analysis to case and control dyads where a Townsend score was available.

The dataset provided by GPRD consisted of 2,954 case dyads and 11,816 control dyads $(4 \times 2,954=11,816)$. The dataset needed to be refined as it included children less than I year old, data on siblings and dyads with less than 12 months of data available. The requirement for 12 months of up to research standard data was the step that most reduced the dataset. This narrowing of the dataset produced 370 case dyads and 1480 control dyads. Our requirement for socio-economic status data reduced the dataset further to 147 cases and 538 control dyads (Figure 1). We examined whether the dataset in which Townsend Score was available, differed from the larger dataset (370 case dyads and 1480 control dyads) by comparing the sex and age of the case children and maternal age and socio-economic status and found no statistical differences between the two datasets.

For this study a special link from mothers to their children was created by GPRD epidemiologists. In some cases there was more than one adult female (the GPRD mother-child link gave any adult female in a household who could, by date of birth, theoretically be the mother). We developed an algorithm using pregnancy related events in the adult females' files to identify the mother and where this was not possible we excluded the dyad. On eight occasions a control mother with two children was matched to two different case children, we excluded the control dyad with the younger child.

We converted all the relevant files into STATA files, and prepared a file for analysis including twelve months of medical records for case dyads that matched our inclusion criteria and four matched control dyads (matched on gender and age of the oldest child that was taken into care).

\section{Data validation}

To validate our cases we sent a questionnaire to General Practitioners of a random sample of 100 cases to confirm that the case child was taken into public care. This was administered by GPRD to protect the identity of the practices and the families.

\section{Identifying variables for analysis}

The systematic review of risk factors associated with children entering public care [27] and clinical experience identified a number of health risk factors to analyse in this primary care dataset. Because previous research has not described these risk factors in routine primary care data, we included all the previously recognised risk factors in our analysis. We included the variables socioeconomic status and maternal age at birth of first child as these are well recognised risk factors for children entering public care and may also confound the association with health risk factors as both variables may influence health seeking behaviour.

The clinical exposures of interest were identified in the database from the clinical (Read/OXMIS) code used by the General Practitioner for a consultation, or from a relevant prescription. 'Sentinel events' were also coded; these were events or illnesses which may be associated with important social markers of vulnerability such as domestic violence. Non clinical exposures of interest in the mother files included maternal age at birth, socioeconomic status, smoking, alcohol use, attendance at Accident and Emergency and referrals to secondary care that suggested a clinical exposure of interest. For the child, the non-clinical exposures included attendances at Accident and Emergency and referrals to secondary care that suggested a clinical exposure of interest.

Using codes identified from the clinical events, therapy and referral files we constructed 58 individual variables which were dichotomised to those individuals with the variable (at any frequency) and those without. Some variables were created by combination of other variables that relate to another aspect of the same issue, details of these composite variables are given in Table 1.

\section{Statistical analysis}

We explored the relationship between each variable and the risk of being taken into public care individually and in a stepwise multivariate conditional logistic regression model to investigate the combined effect of more than one exposure of interest. The variables child maltreatment and social service input (in both mother and child files) were not entered into the model as these correlated very highly with entering care and were not health service use issues. The variables with no odds ratio have a zero score on one of the 2 by 2 table fields and cannot be computed by this method, we assigned a p value for these variables using an exact form of McNemar's Test.

\section{Results}

\section{Data validation}

82 of the 100 questionnaires sent out by GPRD were returned by General Practices. 11 of the 82 simply said that they had no information on the child, usually 
370 case dyads and 1480 control dyads

8 control dyads with
mother used in
another control dyad
deleted

19 case dyads with their 72 matched control dyads where the maternal identity cannot be determined are deleted

37 control dyads where the maternal identity cannot be determined are deleted

351 case dyads and 1400 control dyads

370 case dyads and 1472 control dyads

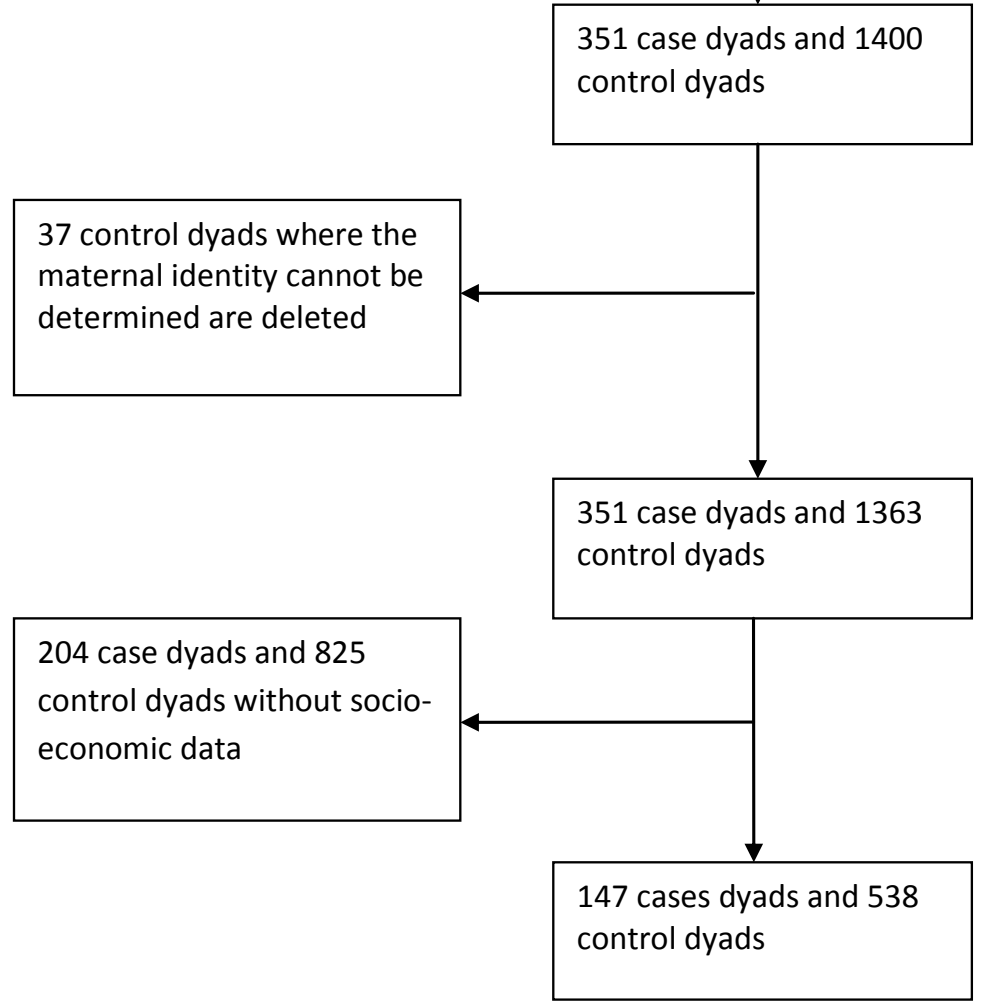

Figure 1 Creating the final dataset

because the child had transferred out of the practice. From the remaining 71 questionnaires, 66 (93\%) confirmed that the child did enter public care. Four children may have been in foster care, and one questionnaire said that the child did not enter public care.

This suggests that approximately $7 \%$ of the dyads included as cases may not correctly be identified. The 
Table 1 Variables created by combining other variables

Title of composite variable
Any social service input

Financial issues

Any nursing input

Any non attendance at primary or secondary care

Child mental illness codes
Created from individual variables

Social service input described in the maternal clinical events file

Social service input in child clinical file

Financial issues in maternal clinical events file

Financial issues in child clinical file

Practice nurse involvement with mother in clinical events file

Health visitor involvement recorded in maternal clinical events file

District nurse involvement with mother in clinical events file

Heath Visitor input in child clinical file,

District or Practice nurse input in child clinical file

Maternal non-attendance at primary or secondary care

Maternal non attendance for cervical smear

Any non attendance at primary or secondary care codes in child clinical file

Immunisation data incomplete in child clinical file

ADHD treatment in child prescription file

Hypnotic in child prescription file

Antipsychotic in child prescription file

Referral to Child and Adolescent Mental Health Services in referral file

Child mental illness codes in child clinical file

Child behavioural issues in child clinical file,

Antidepressant in child prescription file.

Maternal depression in clinical events file

Maternal prescription of an antidepressant

Maternal bipolar disorder in clinical events file

Maternal prescription for treatment of bipolar disorder

Maternal referral to psychiatry

Maternal mental illness in clinical events file

Concern about maternal psychological health

Maternal prescription of anxiolytic

Maternal psychosis in clinical events file

Maternal prescription of an antipsychotic medication

Maternal alcohol misuse

Maternal prescription for treatment of alcohol misuse

Sentinel conditions for alcohol misuse in maternal file

Maternal drug misuse in clinical events file

Prescription of treatment for opiod misuse in maternal therapy file

Sentinel conditions for drug misuse in maternal file

Domestic abuse in maternal clinical events file

Sentinel conditions for trauma in maternal file

Maternal depression in clinical events file

Maternal prescription of an antidepressant

Maternal bipolar disorder in clinical events file

Maternal prescription for treatment of bipolar disorder

Maternal psychosis in clinical events file

Maternal prescription of an antipsychotic medication

Maternal contraception in clinical events file

Maternal prescription of contraceptive error in identification will attenuate any effect size identified in the study.

\section{Demographic information}

The age and gender of case children are described in Figure 2. Children in this study entered care more commonly under the age of six years or older than 14 years.

The age of mothers at the birth of the index child shows a close approximation to a normal distribution for control mothers (Figure 3). However, there are more young case mothers than control mothers and there are more case mothers over the age of 35 . Case mothers are also more likely to be in lower socio-economic quintiles (Figure 4).

Table 2 shows the results of individual variable conditional logistic regression while Table 3 shows the results of the stepwise conditional logistic regression model, created using all the variables significantly associated with children entering public care from Table 2 . Maternal mental illness, maternal age at birth of the child, socio-economic status, maternal drug misuse, non attendance at appointments for mother or child, child mental illness and admission to hospital of the child were all significantly related to the risk of a child entering public 


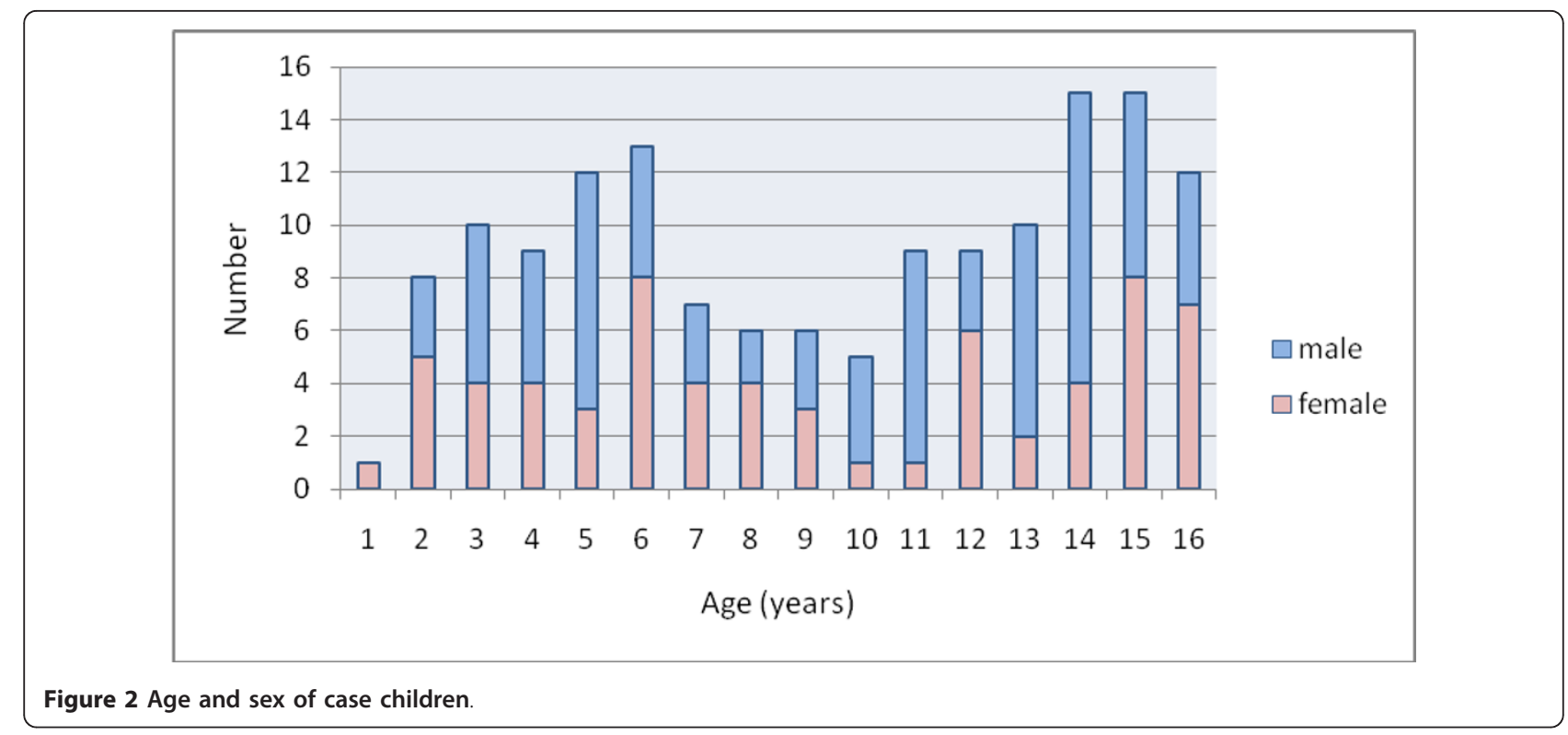

care. Maternal use of primary care contraception services was negatively associated with children entering public care.

\section{Discussion}

Using a primary care database is a novel approach to identifying risk factors for children entering public care. Most of published literature has studied families already in contact with social care services, but such families are a minority of the population, already identified as having a problem of some kind. By contrast, primary care databases include an unselected proportion of the whole population registered with the health service, giving a new perspective on the events leading up to a child being taken into care. A very high percentage of families in the UK are registered with a general practice so identifiable risk factors in routine primary care data could allow access to interventions at a much earlier stage than identification via contact with social care services.

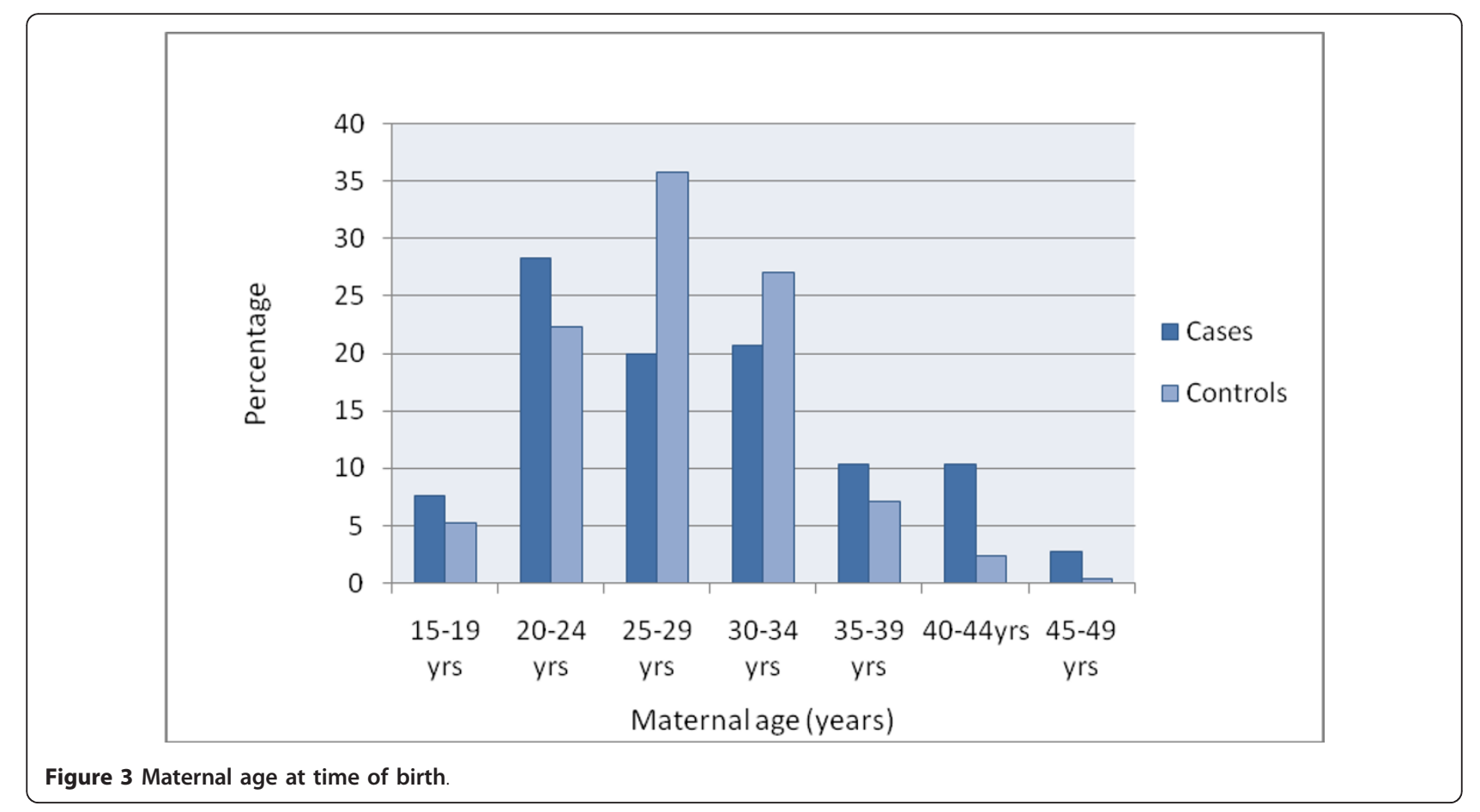




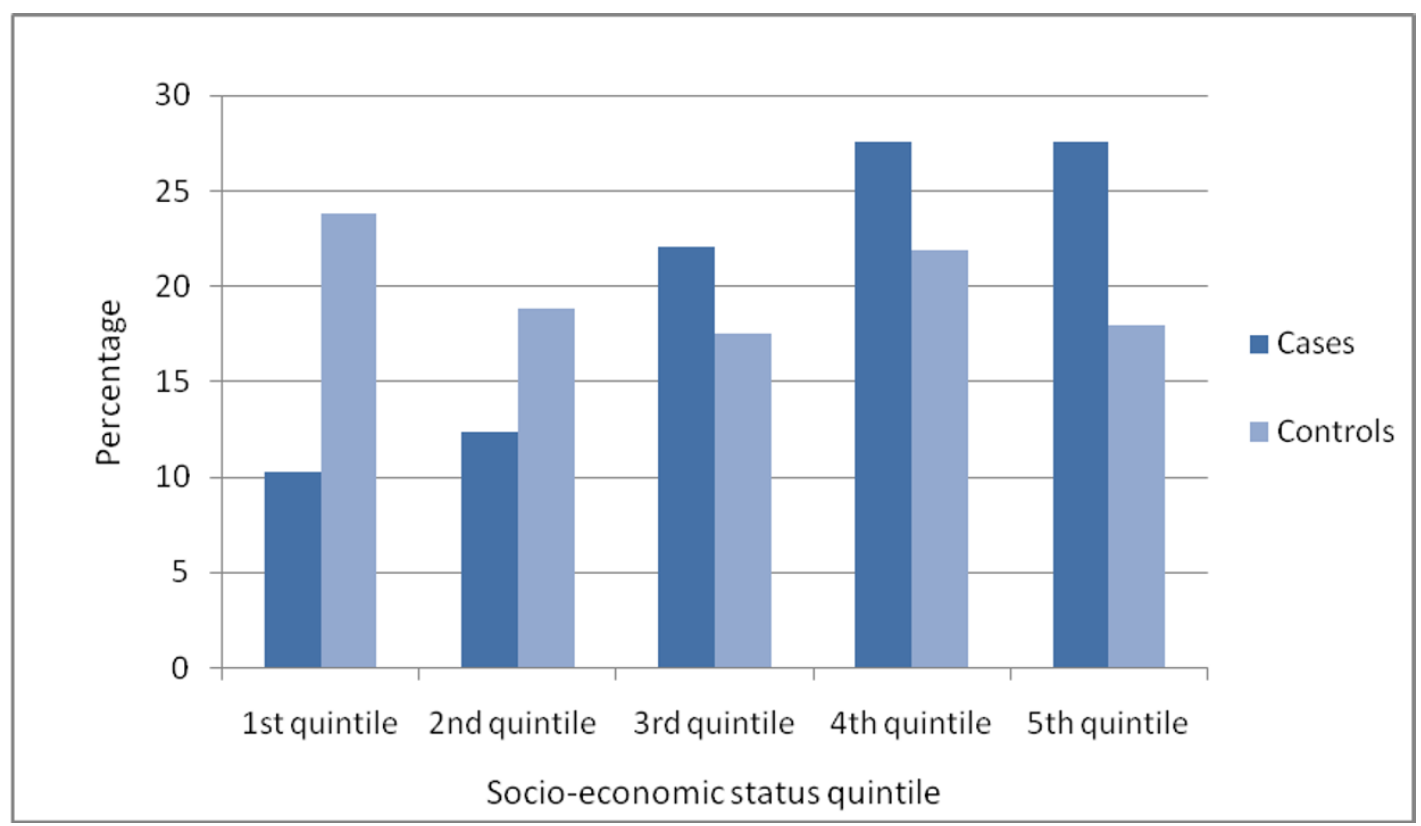

Figure 4 Maternal socio-economic status quintile

We defined a case as a mother child dyad, where the child was the oldest child in the family and both mother and child had 12 months of up to research standard data available. The 12 months requirement was a judgement based on an expectation that most significant health issues would be recorded in the database over that time period. However, excluding children with less than 12 months data considerably reduced the number of included cases. A shorter timeframe would have included more cases and increased the power of the study. It may also have included some highly mobile families that do not stay with the same general practice for 12 months, and research [30,32] suggests that families that are highly mobile have a higher likelihood of children entering public care. However a shorter time frame increases the risk that relevant health issues are not recorded in the primary care record and we considered 12 months to be an appropriate balance between completeness of data and the number of included dyads.

The individual variable results presented in Table 2 shows twenty three variables were significantly associated with children entering public care on univariate analysis, but only eight remained significant in the stepwise multivariate conditional logistic regression model. A striking finding is that individual variables may be highly specific but relatively insensitive. Maternal alcohol misuse is an example; this was described in the 6 case mothers and 1 control mother making the association statistically significant as an individual variable. Other epidemiological evidence suggests that alcohol misuse is under-recorded in the primary care record; the National Institute for Health and Clinical Excellence makes a recommendation on screening for alcohol consumption in primary care in the 2010 guidance on preventing hazardous and harmful drinking [38] and it is possible that some alcohol misuse does not appear in the primary care dataset because general practitioners do not systematically screen for it.

\section{Maternal mental illness}

One of our most important findings is the association of maternal mental illness with children entering public care. Other research has identified an association of parental mental illness with children entering public care, but the definitions of mental illness vary considerably between studies and differ from that used in this research. Franzén et al. used admission to hospital for psychiatric illness, attempted suicide or substance misuse for either parent to create a 'psychosocial risk' variable [29]. This identifies more serious mental illness than we will have identified from primary care records and a level of illness where the possibility of early intervention may already have passed.

Some adult mental health services recognise that their patients may also be parents and that parental mental illness may impact upon parenting [39]. The issue has been highlighted in a study of women with psychotic disorders in south London [40]. 155 (63\%) of these women with psychotic disorders were also mothers but only sixteen of them had a history of having a child 
Table 2 Individual variables conditional logistic regression with the child entering public care

\begin{tabular}{|c|c|c|c|c|}
\hline Exposure of interest & $\begin{array}{l}\text { Cases } \\
\mathrm{n}=147\end{array}$ & $\begin{array}{l}\text { Controls } \\
n=538\end{array}$ & Odds Ratio (95\% Confidence interval) & $P$ value \\
\hline Maternal mental illness & $75(51 \%)$ & $132(25 \%)$ & $3.42(2.29-5.11)$ & $<0.001$ \\
\hline Maternal depression & $52(35 \%)$ & $92(17 \%)$ & $2.76(1.81-4.21)$ & $<0.001$ \\
\hline Maternal referral to psychiatry & $43(28 \%)$ & $58(11 \%)$ & $3.71(2.29-6.01)$ & $<0.001$ \\
\hline Maternal prescription of anxiolytic & $29(20 \%)$ & $24(4 \%)$ & $5.49(3.00-10.1)$ & $<0.001$ \\
\hline Maternal psychosis & $12(8 \%)$ & $6(1 \%)$ & $7.41(2.78-19.8)$ & $<0.001$ \\
\hline Concern about maternal psychological health & $31(21 \%)$ & $55(10 \%)$ & $2.43(1.46-4.04)$ & 0.001 \\
\hline Maternal drug misuse & $7(5 \%)$ & $1(0.2 \%)$ & $27.1(3.33-220)$ & 0.002 \\
\hline Maternal over dose referral & $4(3 \%)$ & $0(0 \%)$ & - & $0.002^{*}$ \\
\hline Maternal alcohol misuse & $6(4 \%)$ & $1(0.2 \%)$ & $23.1(2.78-192)$ & 0.004 \\
\hline Maternal visit to $A+E$ & $17(12 \%)$ & $29(5 \%)$ & $2.39(1.27-4.52)$ & 0.007 \\
\hline Maternal smoking & $33(22 \%)$ & $76(14 \%)$ & $1.88(1.17-3.03)$ & 0.009 \\
\hline Maternal admission to hospital & $6(4 \%)$ & $4(0.7 \%)$ & $6.42(1.59-25.9)$ & 0.009 \\
\hline Relationship issues in maternal file & $5(3 \%)$ & $4(0.7 \%)$ & $4.69(1.26-17.5)$ & 0.021 \\
\hline Maternal contraception & $41(28 \%)$ & $198(37 \%)$ & $0.64(0.43-0.97)$ & 0.035 \\
\hline Child mental illness & $34(23 \%)$ & $43(8 \%)$ & $3.87(2.29-6.53)$ & $<0.001$ \\
\hline Child behavioural issues & $19(13 \%)$ & $18(3 \%)$ & $4.80(2.35-9.82)$ & $<0.001$ \\
\hline Child maltreatment & $20(14 \%)$ & $0(0 \%)$ & - & $<0.001^{*}$ \\
\hline Child admission to hospital & $12(8 \%)$ & $12(2 \%)$ & $3.83(1.68-8.72)$ & 0.001 \\
\hline Child referral to $A+E$ & $16(11 \%)$ & $25(5 \%)$ & $2.74(1.37-5.52)$ & 0.005 \\
\hline Any non attendance at primary or secondary care & $57(39 \%)$ & $101(19 \%)$ & $2.95(1.93-4.52)$ & $<0.001$ \\
\hline Any social service input & $31(21 \%)$ & $4(0.6 \%)$ & $55.8(13.3-233)$ & $<0.001$ \\
\hline Maternal age $15-19$ years old & $13(9 \%)$ & $28(5 \%)$ & $2.63(1.24-5.59)$ & 0.012 \\
\hline Maternal age $20-24$ years old & $41(28 \%)$ & $117(22 \%)$ & $2.34(1.39-3.94)$ & 0.001 \\
\hline Maternal age $25-29$ years old & $30(20 \%)$ & $197(37 \%)$ & 1.00 & - \\
\hline Maternal age $30-34$ years old & $30(20 \%)$ & $142(26 \%)$ & $1.35(0.78-2.34)$ & 0.282 \\
\hline Maternal age 35-39 years old & $15(10 \%)$ & $39(7 \%)$ & $2.74(1.33-5.67)$ & 0.007 \\
\hline Maternal age $40-44$ years old & $14(10 \%)$ & $13(2 \%)$ & $6.97(2.92-16.6)$ & $<0.001$ \\
\hline Maternal age $45-49$ years old & $4(3 \%)$ & $2(0.4 \%)$ & $18.8(1.64-158)$ & 0.017 \\
\hline SES quintile 1 & $15(10 \%)$ & $131(23 \%)$ & 1.00 & \\
\hline SES quintile 2 & $18(12 \%)$ & $104(19 \%)$ & $1.71(0.80-3.67)$ & 0.163 \\
\hline SES quintile 3 & $32(22 \%)$ & $94(17 \%)$ & $3.38(1.69-6.77)$ & 0.001 \\
\hline SES quintile 4 & $41(28 \%)$ & $119(22 \%)$ & $3.92(1.98-7.73)$ & $<0.001$ \\
\hline SES quintile 5 & $41(28 \%)$ & $90(17 \%)$ & $6.51(3.09-13.7)$ & $<0.001$ \\
\hline Maternal smoking cessation & $3(2 \%)$ & $8(1 \%)$ & $1.29(0.34-4.89)$ & 0.71 \\
\hline Maternal sexually transmitted infection & $1(0.7 \%)$ & $19(4 \%)$ & $0.19(0.03-1.47)$ & 0.11 \\
\hline Maternal termination of pregnancy & $2(1 \%)$ & $6(1 \%)$ & $1.28(0.26-6.37)$ & 0.760 \\
\hline Maternal referral to Orthopaedics & $17(11 \%)$ & $38(7 \%)$ & $1.74(0.95-3.20)$ & 0.075 \\
\hline Sentinel conditions for maternal trauma & $5(3 \%)$ & $14(3 \%)$ & $1.37(0.49-3.88)$ & 0.55 \\
\hline Domestic abuse & $7(5 \%)$ & $18(3 \%)$ & $1.53(0.62-3.75)$ & 0.354 \\
\hline Maternal learning difficulties & $1(0.7 \%)$ & $0(0 \%)$ & - & $0.2^{*}$ \\
\hline Maternal bipolar disorder & $2(1 \%)$ & $1(0.2 \%)$ & $8.00(0.73-88.2)$ & 0.09 \\
\hline Sentinel conditions for maternal drug misuse & $1(0.7 \%)$ & $1(0.2 \%)$ & $4.00(0.25-64.0)$ & 0.33 \\
\hline Sentinel conditions for alcohol misuse & $1(0.7 \%)$ & $0(0 \%)$ & - & $0.2^{*}$ \\
\hline Child with scabies & $0(0 \%)$ & $4(0.7 \%)$ & - & $0.409^{*}$ \\
\hline Child with head lice & $9(6 \%)$ & $28(5 \%)$ & $1.35(0.58-3.11)$ & 0.485 \\
\hline Child health surveillance codes & $13(9 \%)$ & $55(10 \%)$ & $0.79(0.33-1.92)$ & 0.604 \\
\hline Ethnicity in maternal file & $0(0 \%)$ & $5(1 \%)$ & - & $0.328^{*}$ \\
\hline Child developmental delay & $4(3 \%)$ & $12(2 \%)$ & $1.29(0.39-4.21)$ & 0.678 \\
\hline Child immunisation data incomplete & $1(0.7 \%)$ & $2(0.4 \%)$ & $2.45(0.14-42.6)$ & 0.539 \\
\hline Immunisation refused & $2(1 \%)$ & $1(0.2 \%)$ & $7.29(0.66-80.8)$ & 0.105 \\
\hline Child referrals to orthopaedics & $1(0.7 \%)$ & $7(1 \%)$ & $0.52(0.06-4.31)$ & 0.551 \\
\hline
\end{tabular}


Table 2 Individual variables conditional logistic regression with the child entering public care (Continued)

\begin{tabular}{lllll}
\hline Other child referrals to secondary care & $18(12 \%)$ & $54(10 \%)$ & $1.27(0.70-2.29)$ & 0.428 \\
Sentinel conditions for child trauma & $3(2 \%)$ & $8(1 \%)$ & $1.26(0.33-4.77)$ & 0.738 \\
Sentinel conditions for child head injury & $2(1 \%)$ & $11(2 \%)$ & $0.68(0.15-3.16)$ & 0.627 \\
Sentinel codes for child burn & $3(2 \%)$ & $2(0.4 \%)$ & $5.36(0.89-32.2)$ & 0.067 \\
Child smoking & $2(1 \%)$ & $4(0.7 \%)$ & $2.93(0.35-10.4)$ & 0.458 \\
Child contraception & $4(3 \%)$ & $7(1 \%)$ & $2.93(0.62-13.9)$ & 0.174 \\
Child pregnancy & $2(1 \%)$ & $4(0.7 \%)$ & $4.45(0.32-62.7)$ & 0.269 \\
Relationship issues in child file & $1(0.7 \%)$ & $1(0.2 \%)$ & $4.00(0.25-64.0)$ & 0.333 \\
Antidepressant prescribed to child & $3(2 \%)$ & $3(0.6 \%)$ & $5.04(0.82-31.0)$ & 0.081 \\
Hypnotic prescribed to child & $8(5 \%)$ & $19(4 \%)$ & $1.63(0.68-3.91)$ & 0.271 \\
Child ADHD treatment & $3(2 \%)$ & $3(0.6 \%)$ & $3.40(0.68-17.1)$ & 0.137 \\
Child alcohol concern & $1(0.7 \%)$ & $2(0.4 \%)$ & $2.00(0.18-22.1)$ & 0.571 \\
Child drug misuse & $1(0.7 \%)$ & $0(0 \%)$ & - & $0.2^{*}$ \\
Health Visitor involvement & $4(3 \%)$ & $5(1 \%)$ & $8.64(0.90-83.0)$ & 0.062 \\
Any nursing input & $4(3 \%)$ & $8(1 \%)$ & $2.36(0.56-10.0)$ & 0.243 \\
Financial issues & $3(2 \%)$ & $5(1 \%)$ & $2.23(0.53-9.35)$ & 0.273 \\
\hline
\end{tabular}

The variables with no odds ratio have a zero score on one of the 2 by 2 table fields and cannot be computed by this method, we assigned a $p$ value for these variables using an exact form of McNemar's Test

enter public care, meaning that $90 \%$ of these women were caring for their own children [40]. The fear of children entering public care is felt especially in the context of episodes of in-patient care and although not the only reason why parents with mental illness are reluctant to ask for help with parenting, it may be the most pervasive. People with mental illness face many challenges including poverty, emotional distress, cognitive impairment, medication side effects and perceived stigma, so perhaps it is unsurprising that few people with mental illness seek or receive specific help with parenting.
There is a contrast with the resources dedicated to helping these patients with other issues such as securing benefits, finding accommodation, maintaining gainful occupation and adhering to medication [41].

The association of maternal mental with children entering public care is a potentially important finding of this study with implications for adult psychiatry and primary care services. However, it is possible that the observed relationship between an increased risk of children going into care and maternal mental illness is due to confounding by some other variable. For example,

Table 3 Forward selection conditional logistic regression model

\begin{tabular}{lllll}
\hline Exposure of interest & $\begin{array}{l}\text { Cases } \\
\mathbf{n = 1 4 7}\end{array}$ & $\begin{array}{l}\text { Controls } \\
\mathbf{n}=\mathbf{5 3 8}\end{array}$ & Odds ratio (95\% confidence intervals & P value \\
\hline Maternal mental illness & $75(51 \%)$ & $132(25 \%)$ & $2.51(1.55-4.05)$ & $<0.001$ \\
Maternal age 15-19 years old & $31(21 \%)$ & $4(0.6 \%)$ & $2.45(1.11-5.42)$ & 0.027 \\
Maternal age 20-24 years old & $13(9 \%)$ & $28(5 \%)$ & $2.37(1.38-4.06)$ & 0.002 \\
Maternal age 25-29 years old & $41(28 \%)$ & $117(22 \%)$ & 1.00 & 0.236 \\
Maternal age 30-34 years old & $30(20 \%)$ & $197(37 \%)$ & $1.43(0.81-2.53)$ & 0.222 \\
Maternal age 35-39 years old & $30(20 \%)$ & $142(26 \%)$ & $2.90(1.36-6.18)$ & 0.006 \\
Maternal age 40-44 years old & $15(10 \%)$ & $39(7 \%)$ & $6.21(2.50-15.4)$ & $<.001$ \\
Maternal age 45-49 years old & $14(10 \%)$ & $13(2 \%)$ & $24.4(2.30-258)$ & 0.008 \\
SES quintile 1 & $15(10 \%)$ & $131(23 \%)$ & 1.00 & - \\
SES quintile 2 & $18(12 \%)$ & $104(19 \%)$ & $2.41(1.01-5.74)$ & 0.047 \\
SES quintile 3 & $32(22 \%)$ & $94(17 \%)$ & $2.83(1.25-6.39)$ & 0.012 \\
SES quintile 4 & $41(28 \%)$ & $119(22 \%)$ & $3.40(1.58-7.32)$ & 0.002 \\
SES quintile 5 & $41(28 \%)$ & $90(17 \%)$ & $7.14(2.92-17.4)$ & $<0.001$ \\
Maternal drug misuse & $7(5 \%)$ & $1(0.2 \%)$ & $28.8(2.29-363)$ & 0.009 \\
Any non attendance at primary or secondary care & $57(39 \%)$ & $101(19 \%)$ & $2.42(1.42-4.14)$ & 0.001 \\
Child mental illness & $34(23 \%)$ & $43(8 \%)$ & $2.65(1.42-4.96)$ & 0.002 \\
Maternal contraception & $41(28 \%)$ & $198(37 \%)$ & $0.52(0.31-0.87)$ & 0.013 \\
Child admission to hospital & $12(8 \%)$ & $12(2 \%)$ & $3.31(1.21-9.02)$ & 0.019 \\
\hline
\end{tabular}


Diaz-Caneja and Johnson reported that mothers who felt it was probable that their children would be taken into care became concerned, anxious or depressed and sought mental health support [42]. Further research in large cohorts may help to disentangle these factors.

\section{Maternal age at birth of child}

Both younger and older mothers were significantly more likely to have their children enter public care, although the absolute number of older mothers was small. A number of previous studies have identified young mothers as a group with an increased risk of children entering public care $[29,31]$ and two studies identified older mothers at increased risk also [30,33]. Of course teenage motherhood is not necessarily bad [43] and most pregnant teenagers do not have children that enter public care. However young motherhood has been associated with a range of negative outcomes in the USA and the UK, and both counties target this group of mothers for interventions $[44,45]$.

\section{Socio-economic status}

Low socio-economic status has been recognised as an important risk factor associated with children entering public care in many studies. In the UK context, the work of Bebbington and Miles [28] has been influential in social care and government guidance and policy development $[46,47]$. Their findings were replicated in Sweden by Franzén, Vinnerljung and Hjern [29] and it is clear that this is an important risk factor. Figure 4 shows that, while control families were approximately equally distributed across the quintiles of the Townsend score, case families showed an increase from the $1^{\text {st }}$ to $4^{\text {th }}$ quintiles and remained high in the $5^{\text {th }}$ (most disadvantaged) quintile.

The association of material deprivation with many indices of poor health has been frequently reported in the United Kingdom [48-53] and strategies to reduce social inequality remain necessary. There has been vigorous debate on the mechanisms, models and causal pathways by which material deprivation exerts its negative impact on a wide range of child health outcomes. As many people experience multiple disadvantage and deprivation, Spencer suggests that single causal factors are of limited value and theoretical models which accommodate the cumulative effects of various factors over time are more likely to offer a fruitful approach to explaining the relationship between socio-economic status and health [50].

The relationship between socio-economic status and health service use is an important issue. It could be that low socio-economic status is the prime driver of children entering public care, and patterns of health service use simply reflect the consequences of deprivation.
However Franzén found a significant association between psychosocial markers and children entering care after adjusting for socio-economic status [29] and in this study variables for health service use have a significant relationship with risk of a child entering care after adjusting for socio-economic status (Table 3).

A plausible scenario is that there are several routes that lead to children entering public care and the risk factors we have identified are all pathways to children entering public care. It is possible that the stresses are additive with an aggregate of stressors leading to children entering public care $[54,55]$.

\section{Other maternal factors}

Eight mothers of the mothers in this study were recorded as having a drug misuse problem; seven of them had children who entered public care. In the USA, parental problem drug use is one of the main reasons for children entering public care [56]. The Advisory Council on the Misuse of Drugs reported that 2-3\% of all children under the age of 16 have parents with drug problems in the UK [57], which suggests that we have not identified some mothers with drug problems, maybe because most drug use is not recorded in primary care. Percy et al. call for more recognition of the needs of dependent children within adult treatment services working with parents [58]. This will probably require much closer working between addiction services and primary care.

Maternal non-attendance at appointments and failure to use contraceptive services were both significantly related to a higher risk of children being taken into care. These variables may be indicators of a chaotic lifestyle. Successful engagement with the National Health Service requires some planning and non-attendance at appointments is common at secondary care out-patient clinics, varying between 5 and $34 \%$, but is more infrequent in primary care at $3-6.5 \%[59,60]$. Non attendance is a recurring theme in serious case reviews of child maltreatment and many NHS organisations have now developed non attendance policies.

\section{Child related factors}

The children who entered public care were more than 2.5 times as likely to have a mental illness in the preceding 12 months as control children. Children in difficult life circumstances may express their unhappiness in ways that result in presentation to health services. Experiences of abuse are associated with mental ill health in children, and a recent systematic review demonstrated that the strongest associations between parent-child relationships and psychiatric disorder in adult offspring were for the most severe forms of physical and sexual abuse, and neglect in childhood [61]. 
An Australian study of the mental health of 347 children in public care found that the strongest pre-care predictor of children's mental ill-health was 'age at entry to care', an indicator of overall exposure to precare adversity [62]. Mental illness could be reduced if services can identify these children earlier, but it is also important to avoid false positive interventions that result in children being improperly placed in public care.

Case children were more than three times as likely as control children to have been in hospital during the 12 month period, although admission was an unusual event. Only $8 \%$ of case and $2 \%$ of control children were hospitalised. It may be that it is the admission itself that identifies problems in the family for the first time and leads to social care input.

\section{Conclusion}

Research, using social care or government datasets, has identified risk factors associated with children entering public care but the utility of risk factors in clinical practice is not established. Using primary care data from the General Practice Research Database, this study identifies differences in health service use in mother child pairs where children enter public care after controlling for maternal age and socio-economic status. Maternal mental illness, maternal drug use, non attendance at appointments, child mental illness and child admission to hospital were all significantly associated with children entering public care and thus populations can be identified that could be targeted for secondary prevention strategies.

Practitioners, particularly general practitioners and adult mental health workers need to recognise that their patients may also be mothers and their illnesses may impact on their ability to parent; As Howard said 'parenting is not generally considered to be a mental health issue unless child protection concerns are raised' [63].

Primary care practitioners need to screen for and record to record risk factors as it is likely that there is under reporting of risk factors in the clinical record.

\section{Sponsor statement}

This study is based in part on data from the Full Feature General Practice Research Database obtained under licence from the UK Medicines and Healthcare Products Regulatory Agency (MHRA). However, the interpretation and conclusions contained in this study are those of the authors alone. Access to the GPRD database was funded through the Medical Research Council's licence agreement with MHRA.

Dr D E Simkiss is the guarantor for this manuscript.

\section{Acknowledgements}

The authors would like to acknowledge the contribution made by the staff at the General Practice Research Database and Tarita Murray-Thomas in particular for all her help in creating the initial dataset and for assistance with questions during analysis.

\section{Author details}

${ }^{1}$ Health Sciences Research Institute, Warwick Medical School, University of Warwick, Coventry CV47AL, UK. ${ }^{2}$ School of Health and Social Studies, University of Warwick, Coventry CV4 7AL, UK. ${ }^{3}$ Health Sciences Research Institute, Warwick Medical School, University of Warwick, Coventry CV47AL, UK. ${ }^{4}$ Health Sciences Research Institute, Warwick Medical School, University of Warwick, Coventry CV47AL, UK.

\section{Authors' contributions}

All the authors of this paper have made a substantial contribution to the conception and design, or analysis and interpretation of data, each has been involved in drafting the article or revising it critically for important intellectual content and each has given final approval of this version to be published.

\section{Competing interests}

The authors declare that they have no competing interests.

Received: 8 August 2011 Accepted: 16 March 2012

Published: 16 March 2012

\section{References}

1. Polnay L, Ward H: Promoting the health of looked after children, Government proposals demand leadership and a culture change. BMJ 2000, 320(7236):661-662.

2. Ford T, Vostanis P, Meltzer H, Goodman R: Psychiatric disorder among British children looked after by local authorities: comparison with children living in private households. British Journal of Psychiatry 2007, 190(4):319-325.

3. Kerker BD, Dore MM: Mental Health Needs and Treatment of Foster Youth: Barriers and Opportunities. American Journal of Orthopsychiatry 2006, 76(1):138-147.

4. Pilowsky DJ, Wu L-T: Psychiatric symptoms and substance use disorders in a nationally representative sample of American adolescents involved with foster care. Journal of Adolescent Health 2006, 38(4):351-358.

5. Tarren-Sweeney M: The mental health of children in out-of-home care. Current Opinion in Psychiatry 2008, 21(4):345-349.

6. Tine $E$, Mette L: Prevalence of mental health problems among children placed in out-of-home care in Denmark. Child \& Family Social Work 2009, 14(2):156-165.

7. Hill CM, Mather M, Goddard J: Cross sectional survey of meningococcal C immunisation in children looked after by local authorities and those living at home. BMJ 2003, 326(7385):364-365.

8. Ashton-Key $M$, Jorge $E$ : Does providing social services with information and advice on immunisation status of "looked after children" improve uptake? Arch Dis Child 2003, 88(4):299-301.

9. Williams J, Jackson S, Maddocks A, Cheung WY, Love A, Hutchings H: Casecontrol study of the health of those looked after by local authorities. Arch Dis Child 2001, 85(4):280-285.

10. Thompson JRG, Auslander WF: Risk factors for alcohol and marijuana use among adolescents in foster care. Journal of Substance Abuse Treatment 2007, 32(1):61-69.

11. Vaughn MG, Ollie MT, McMillen JC, Scott L Jr, Munson M: Substance use and abuse among older youth in foster care. Addictive Behaviors 2007, 32(9):1929-1935.

12. Wall AE, Kohl PL: Substance Use in Maltreated Youth: Findings From the National Survey of Child and Adolescent Well-Being. Child Maltreat 2007, 12(1):20-30.

13. Knight A, Chase E, Aggleton P: Teenage pregnancy among young people in and leaving care: Messages and implications for foster care. Adoption \& Fostering Journal 2006, 30:58-69.

14. Vinnerljung B: Franzeén E, Danielsson M: Teenage parenthood among child welfare clients: A Swedish national cohort study of prevalence and odds. Journal of Adolescence 2007, 30(1):97-116. 
15. Vinnerljung B, Sallnäs M: Into adulthood: a follow-up study of 718 young people who were placed in out-of-home care during their teens. Child \& Family Social Work 2008, 13(2):144-155.

16. National Institute for Heath and Clinical Excellence/Social Care Institute for Excellence. NICE Public Health Guidance 28: Promoting quality of life for looked after children London; 2010.

17. Department of Health: Promoting the health and wellbeing of looked after children London; 2009.

18. Department for Education and Skills: Every Child Matters London; 2003.

19. Department for Children Schools and Families: Outcome indicators for children looked after: twelve months to 30 September 2009 London; 2010.

20. Franzén F, Vinnerljung B: Foster children as young adults: many motherless, fatherless or orphaned: a Swedish national cohort study. Child \& Family Social Work 2006, 11(3):254-263.

21. Hjern A, Vinnerljung B, Lindblad F: Avoidable mortality among child welfare recipients and intercountry adoptees: a national cohort study. Journal of Epidemiology \& Community Health 2004, 58(5):412-417.

22. Viner RM, Taylor B: Adult Health and Social Outcomes of Children Who Have Been in Public Care: Population-Based Study. Pediatrics 2005, 115(4):894-899.

23. Vinnerljung B, Hjern A, Weitoft GR, Franzén E, Estrada F: Children and young people at risk (Chapter 7). International Journal of Social Welfare 2007, 16(1):163-202.

24. Dimigen G, Del Priore C, Butler S, Evans S, Ferguson L, Swan M: Psychiatric disorder among children at time of entering local authority care: questionnaire survey. BMJ 1999, 319(7211):675.

25. Sempik J, Ward H, Darker I: Emotional and Behavioural Difficulties of Children and Young People at Entry into Care. Clinical Child Psychology and Psychiatry 2008, 13:221-233.

26. Steele JS, Buchi KF: Medical and mental health of children entering the Utah foster care system. Pediatrics 2008, 122(3):e703-e709.

27. Simkiss DE, Stallard N, Thorogood M: A systematic review of the risk factors associated with children entering out-of-home care Submitted to Child: Care, Health and Development; 2011.

28. Bebbington A, Miles J: The background of children who enter local authority care. British Journal of Social Work 1989, 19:349-368.

29. Franzén E, Vinnerljung B: Hjern: The Epidemiology of Out-of-Home Care for Children and Youth: A National Cohort Study. British Journal of Social Work 2008, 38(6):1043-1059

30. Höglund-Dávila, Landgren-Möller : 'Vilka barn omhandertas av samhallet?' ['Which children are taken into societal care?']. In Livsforloppsanalys. Bakgrundsmaterial fran demografiska funktionen. Edited by: Qvist J. Stockholm; 1991:45-65

31. Needell B, Barth RP: Infants entering foster care compared to other infants using birth status indicators. Child Abuse \& Neglect 1998, 22(12):1179-1187.

32. Friedlaender EY, Rubin DM, Alpern ER, Mandell DS, Christian CW, Alessandrini EA: Patterns of health care use that may identify young children who are at risk for maltreatment. Pediatrics 2005, 116(6):1303-1308.

33. Kalland M, Sinkkonen J, Gissler M, Merilainen J, Siimes MA: Maternal smoking behavior, background and neonatal health in Finnish children subsequently placed in foster care. Child abuse \& neglect 2006, 30(9):1037-1047.

34. Christoffersen MN, Soothill K: The long-term consequences of parental alcohol abuse: a cohort study of children in Denmark. Journal of Substance Abuse Treatment 2003, 25(2):107-116.

35. Ogunyemi D, Hernandez-Loera GE: The impact of antenatal cocaine use on maternal characteristics and neonatal outcomes. The Journal of Maternal-Fetal \& Neonatal Medicine 2004, 15(4):253-259.

36. General Practice Research Database. [http://www.cprd.com/home/]

37. Townsend P, Phillimore P, Beattie A: Health and deprivation: inequality in the North London; 1988

38. National Institute for Health and Clinical Excellence: NICE Public Health Guidance 24:Alcohol use disorders: Preventing the development of hazardous and harmful drinking London: National Institute of Health and Clinical Excellence; 2010

39. Royal College of Psychiatrists: Patients as parents: addressing the needs, including the safety, of children whose parents have mental illness London; 2002.
40. Howard LM, Kumar R, Thornicroft G: Psychosocial characteristics and needs of mothers with psychotic disorders. British Journal of Psychiatry 2001, 178:427-432.

41. Appleby L: The National Service Framework for Mental Health-Five years On London; 2004.

42. Diaz-Caneja A, Johnson S: The views and experiences of severely mentally ill mothers-a qualitiative study. Soc Psychiatry Psychiatr Epidemiol 2004, 39:472-482.

43. Rolfe A: 'You've got to grow up when you've got a kid': Marginalized young women's accounts $\mathrm{f}$ motherhood. Journal of Community \& Applied Social Psychology 2008, 18(4):299-314.

44. Olds DL, Hill PL, O'Brien R, Racine D, Moritz P: Taking preventive intervention to scale: The nurse-family partnership. Cognitive and Behavioral Practice 2003, 10(4):278-290.

45. Department of Health: Healthy Child Programme: pregnancy and the first five years of life London; 2009.

46. Department of Health: Department for Education and Employment Home Office: Framework for assessment of children in need and their families. London; 2000

47. Children's Workforce Development Council: The Common Assessment Framework for children and young people Leeds 2009.

48. Black D, Morris JN, Smith C, Townsend P: Report of the Working Party on Inequalities in Health. London 1980.

49. Whitehead M: The Health Divide London; 1987.

50. Spencer N: Poverty and child health Oxford; 1996

51. Acheson D: Independent Inquiry into Inequalities in Health Report London; 1998.

52. Spencer N: Social, Economic, and Political Determinants of Child Health. Pediatrics 2003, 112(3):704-706.

53. Marmot M: Fair Society University College London: Healthy Lives; 2010.

54. Rutter M, Pickles A, Murray R, Eaves L: Testing hypotheses on specific environmental causal effects on behavior. Psychological Bulletin 2001, 127(3):291-324.

55. Delfabbro P, Borgas M, Rogers N, Jeffreys H, Wilson R: The social and family backgrounds of infants in South Australian out-of-home care 2000-2005: Predictors of subsequent abuse notifications. Children and Youth Services Review 2009, 31(2):219-226.

56. Child Welfare League of America: Alcohol and other Drug Survey of State Child Welfare Agencies Washington; 1998.

57. Advisory Council on the Misuse of Drugs: Hidden Harm-responding to the needs of children of problem drug users London; 2003.

58. Percy A, Thornton M, McCrystal P: The extent and nature of family alcohol and drug use: findings from the belfast youth development study. Child Abuse Review 2008, 17(6):371-386.

59. Andrews R, Morgan JD, Addy DP, McNeish AS: Understanding nonattendance in outpatient paediatric clinics. Archives of Disease in Childhood 1990, 65(2):192-195.

60. Sharp DJ, Hamilton W: Non-attendance at general practices and outpatient clinics. BMJ 2001, 323(7321):1081-1082.

61. Weich S, Patterson J, Shaw R, Stewart-Brown S: Family relationships in childhood and common psychiatric disorders in later life: systematic review of prospective studies. The British Journal of Psychiatry 2009, 194(5):392-398.

62. Tarren-Sweeney M: Retrospective and concurrent predictors of the mental health of children in care. Children and Youth Services Review 2008, 30(1):1-25.

63. Howard L: Psychotic disorders and parenting-the relevance of patient's children for general adult psychiatric services. Psychiatric Bulletin 2000, 24(9):324-326.

\section{Pre-publication history}

The pre-publication history for this paper can be accessed here: http://www.biomedcentral.com/1472-6963/12/65/prepub

doi:10.1186/1472-6963-12-65

Cite this article as: Simkiss et al: Health service use in families where children enter public care: a nested case control study using the General Practice Research Database. BMC Health Services Research 2012 12:65. 